with some mothers having no daughters and emigrants taking with them only a few of the genes of their homeland when they left, mean that most mitochondrial lineages have been lost. Unfortunately, and in spite of all the publicity about the discovery of the Earth mother, Eve was a statistical artefact.

However, her biography makes a good story. The latest idea is that the spread of one mother's genes accompanied the origin of language; a theory reported here as "scientists claim woman had the first word". This and new work on the Y chromosome means that perhaps we will soon see a book reporting not only where Eve met Adam but what they said to each other.

J. S. Jones is in the Department of Genetics and Biometry, University College London, London NW1 $2 H E$, UK.

\section{Mirror images}

\section{P. V. E. McClintock}

Reflections on Liquid Helium. By E. L. Andronikashvili. AIP: 1990. Pp. 317. $£ 45, \$ 60$.

THE non-appearance of invited Soviet speakers at international conferences an all-too-familiar feature of the international scientific scene during the several decades of the cold war - and the resultant relative isolation of Soviet science inevitably led to inefficiences, infelicities and lost opportunities. One thinks, for example, of the numerous cases of wasteful repetition of work already completed and published on the other side of the iron curtain, of delayed recognition for important achievements, and incorrect attributions of priority in discovery.

Much of the excellent Soviet science of this period has consequently been shrouded in a certain mystery, for those in the West, with many of the chief personae becoming familiar in name only, and years afterwards. This is especially true in the case of the (enormous) Soviet contributions to low-temperature physics, and in particular to the understanding of superfluid helium. The name (but not the person) of Andronikashvili is well known to every low-temperature physicist on account of his famous experiment in which he measured directly the relative proportions of the two components of liquid helium below its superfluid transition temperature at 2.17 kelvin: the normal component (which behaves like an ordinary liquid) and the superfluid component (which displays a variety of exotic properties such as inviscid, frictionless flow).

What Élevter Luarsabovich Androni- kashvili achieved by managing to complete his Reflections on Liquid Helium before his death last year has been, in effect, to "take the lid off" half a century of Soviet low-temperature physics, revealing not only the circumstances of the particular experiment which made him famous, but also the personalities, relationships, arguments, intrigues, motivations and the many difficulties involved in practicing experimental scientific research at the highest level within a closed society. In content, the book represents a kind of scientific autobiography but, as Russell Donnelly points out in his foreword, it is written much more in the style of a novel.

The story opens with Andronikashvili at the age of 29 , already established in a chair at the University of Tbilisi in Georgia, but in great trepidation agonizing about whether or not to dare to apply for permission to spend a year in Kapitsa's famous Institute for Physical Problems in Moscow. He was eventually persuaded by his sister-in-law Viva to do so, and the decision changed his life. It also, to a significant extent, modified the future of low-tempertaure physics. The tale continues with vivid descriptions of Andronikashvili's time in the institute, his enforced return to Tbilisi, and his subsequent (successful) fight to escape from his administrative and political responsibilities for enough of the time to maintain contact with the world of research. Such a succinct summary of the book must make it appear tame but, in reality, it is anything but that.

Most of Andronikashvili's Reflections is devoted to discussions of his scientific and social relationships with colleagues, rivals, friends and visitors, and with his hosts in the numerous departments and institutes in the West that he was eventually able to

\section{New Journals}

This year Nature's annual new journals review supplement will appear in the issue of 11 October. Publishers and learned societies are invited to submit journals for review, taking note of the following criteria:

- Journals which first appeared after June 1988 , and which issued at least four separate numbers by the end of April 1990, will be considered for review. The deadline for submission is the end of June.

- Journals covering any aspect of science are eligible, although those dealing with clinical medicine, engineering and pure mathematics are excluded, as are publications of abstracts. - Frequency of publication must be at least three times a year.

- The main language used must be English. Translation journals in English are eligible.

When submitting journals for review, please send at least four different issues (the first, the most recent and any two others) of each title as soon as possible to: Book Review Editor, Nature, 4 Little Essex Street, London WC2R 3LF, UK or 1137 National Press Building, Washington DC 20045, USA. visit. The story is very much a human one, and is told in large part though quotations of direct speech. The reader may wonder about the accuracy with which conservations are being remembered, in some cases, almost 50 years after the event; but such reservations seem petty in the face of the liveliness, vigour and intrinsic interest of the narrative itself. It provides a fascinating account, from the viewpoint of a participant, of how discoveries are really made - including the errors, arguments, misapprehensions and false starts - as opposed to the tidy post hoc rationalization that is usually all that is embodied in a scientific paper. The book will thus be of interest to historians and philosophers of science, as well as to low-temperature physicists.

There are scores of entertaining anecdotes, and there are critical and often highly amusing descriptions of the (literally) hundreds of people whom Andronikashvili met or worked with in the course of his scientific career. The latter include a galaxy of well-known names, such as Kapitsa, Landau, Bogolyubov, Peshkov, Khalatnikov, Frenkel, Shal'nikov, Bohr, Peierls, Allen, Feynman, Bardeen, Abraham, Hall and Vinen - to name only a tiny sample. Andronikashvili's character studies of close associates, for example Kapitsa and Landau, are highly illuminating. In other cases, where his trenchant remarks are based on slighter evidence (such as a single meeting at a conference) they can occasionally seem a little unfair. The persons portrayed are usually highly recognizable, though, and the book will certainly provide a source of considerable amuse ment to the victims' colleagues and friends.

One of these victims of an Andronikashvili vignette was recently heard to remark good-humouredly: "but he was a pompous little man himself, anyway". Perhaps he was - I never had the privilege (or, possibly, the liability) of meeting him - but he was clearly much more besides. Inevitably, Reflections tells us at least as much about its author as about the people he set out to describe. Andronikashvili was clearly a complex and interesting character with coexisting, seemingly contradictory, traits: of impetuous enthusiasm, coupled with meticulous attention to detail; of brusqueness and intolerance, but great personal kindness; of pride and a perhaps overly pronounced sense of hierarchy, mercifully punctured by a well-developed sense of humour. He was also a distinguished scientist who has left a permanent mark on lowtemperature physics and on science in Georgia.

P. V. E. McClintock is in the Physics Department, Lancaster University, Lancaster LA1 $4 Y B, U K$. 